\title{
Recombinant luciferase-expressing murine gammaherpesvirus 68 as a tool for rapid antiviral screening
}

\author{
K. BRIESTENSKÁ ${ }^{1}$, V. ŠAMŠULOVÁ², M. POLÁKOVÁ J. MISTRÍKOVÁ ${ }^{1,4^{*}}$
}

\begin{abstract}
${ }^{1}$ Department of Microbiology and Virology, Faculty of Natural Sciences, Comenius University in Bratislava, Ilkovičova 6, 84215 Bratislava, Slovak Republic; ${ }^{2}$ Department of Organic Chemistry, Faculty of Science, Palacky University Olomouc, Olomouc, Czech Republic; ${ }^{3}$ Institute of Chemistry, Center for Glycomics, Slovak Academy of Sciences, Bratislava, Slovak Republic; ${ }^{4}$ Institute of Virology, Biomedical Research Center of the Slovak Academy of Sciences, Dúbravská cesta 9, 84505 Bratislava, Slovak Republic
\end{abstract}

\begin{abstract}
Summary. - Murine gammaherpesvirus 68 (MHV-68) provides a valuable tool to screen novel therapeutic strategies against oncogenic gammaherpesviruses. The development and characterization of antiviral agents usually depend on appropriate screening assays. The aim of this study was to develop rapid and sensitive method for testing antiviral compounds against gammaherpesviruses. For this purpose, a recombinant MHV-68 expressing firefly luciferase (MHV-68/LUC) was constructed. The conditions for MHV-68/LUC infection in Vero cells suitable for novel antiviral screening assay in 96-well plate format were then optimized. The sensitivity of MHV-68/LUC to acyclovir (ACV) and ganciclovir (GCV) was measured by the optimized luciferase activity reduction assay. The $50 \%$ inhibition concentration $\left(\mathrm{IC}_{50}\right.$ ) values for $\mathrm{ACV}$ and $\mathrm{GCV}$ were comparable to those determined by conventional plaque reduction assay. Therefore, the luciferase activity reduction assay can efficiently replace the plaque reduction assay. The great advantages of novel assay are represented by the significant reduction in assay time and rapid and objective measurement of the assay. In order to evaluate whether the luciferase activity reduction assay could be used as a screening system for novel antivirals, newly synthesized quinolone/quinoline derivatives were tested for their effects on the replication of MHV-68/LUC in vitro. The compound 2-(1-(b-D-Xylopyranosyl)-1,2,3-triazol-4-yl)-3,4-dibenzyloxy-quinoline showed significant antiviral activity and its $\mathrm{IC}_{50}$ against MHV-68/LUC was estimated to be $1,76 \mu \mathrm{g} / \mathrm{ml}$. However, this compound was not suitable for in vivo testing due to its narrow selectivity index $(\mathrm{SI}=11)$.
\end{abstract}

Keywords: MHV-68; antiviral screening; luciferase; quinolone/quinoline derivatives

\section{Introduction}

The vast majority of the world's population is infected with herpesviruses. Herpesviruses exhibit two distinct phases of

${ }^{*}$ Corresponding author. E-mail: virumis@savba.sk; phone: +4212-59302-426, +421-2-54773172.

Abbreviations: $\mathrm{ACV}=$ acyclovir; $\mathrm{CC}_{50}=50 \%$ cytotoxic concentration; $\mathrm{CPE}=$ cytopathic effect; DMSO = dimethyl sulfoxide; $\mathrm{EBV}=$ Epstein-Barr virus; GCV = ganciclovir; hpi = hours post infection; $\mathrm{IC}_{50}=50 \%$ inhibitory concentration; KSHV = Kaposi's sarcoma-associated herpesvirus; $\mathrm{LDH}=$ lactate dehydrogenase; MHV-68 = murine gammaherpesvirus 68; MHV-68/LUC = recombinant luciferase-expressing MHV-68; MOI = multiplicity of infection; MTT = 3-(4,5-dimethylthiazol-2-yl)-2,5-diphenyltetrazolium bromide; RLU = relative light units; SI = selectivity index the life cycle, known as lytic replication and latency. Switching between these two phases has advantageously allowed herpesviruses to efficiently establish life-long persistent infections in hosts. Persistent infections are usually asymptomatic. However, in some cases the persistence of herpesvirus infection may result in tumorigenesis (Pellett and Roizman, 2013). Human gammaherpesviruses Epstein-Barr virus (EBV) and Kaposi's sarcoma-associated herpesvirus (KSHV) are two of the most prominent infectious agents associated with variety of lymphoproliferative disorders. EBV, the etiological agent of infectious mononucleosis, is related to Burkitt's lymphoma, Hodgkin's lymphoma, nasopharyngeal carcinoma, and posttranplantation lymphoproliferative disease (Pagano, 1999; Kutok and Wang, 2006; Odumade et al., 2011). KSHV is associated with Kaposi's sarcoma, 
multicentric Castleman's disease, and primary effusion lymphoma (Cesarman, 2014; Dittmer and Damania, 2016; Jha et al., 2016).

Most of the currently available antiherpetic drugs are nucleoside analogues, which act as inhibitors of viral DNA polymerase. Although numerous antiviral agents have proven to be effective inhibitors of EBV and KSHV replication in vitro, no drug has been approved yet for the treatment of gammaherpesvirus infections (Coen et al., 2014; Pagano et al., 2018). Therefore, there is a real need to identify new compounds with high effectivity and selectivity against human gammaherpesviruses. However, the development of novel antiviral agents has been limited due to the lack of efficient gammaherpesvirus replication system. Murine gammaherpesvirus 68 (MHV-68) is a natural pathogen of small rodents (Blaškovič et al., 1980) and is biologically and genetically related to human gammaherpesviruses. MHV-68 provides a useful tool to screen novel chemotherapeutic and prophylactic strategies to combat gammaherpesviruses (Simas and Efstathiou, 1998; Stewart, 1999; Mistríková et al., 2000). In contrast to most gammaherpesviruses, MHV-68 forms a fully productive infection in conventional cell cultures and induces characteristic cytopathic effect (CPE) (Svobodová et al., 1982). Thus, CPE reduction assay (Neyts and De Clercq, 1998; Medveczky et al., 2004; Coen et al., 2013) or plaque reduction assay (Smee et al., 1997; Barnes et al., 1999; Cho et al., 2013; Kang et al., 2017, 2018) can be used for evaluation of the susceptibility of the MHV-68 to antiviral agents. These assays represent the gold standard screening methods and are relatively simple to perform. However, they are labor-intensive, time-consuming and usually based on highly subjective observations. CPE reduction assay and plaque reduction assay are best suited for small numbers of specimens as they are difficult to automate. In order to increase the capacity of testing newly synthesized compounds, it is necessary to improve the efficiency and the speed of antiviral screening methods.

Recombinant viruses carrying reporter genes may greatly facilitate screening and identification of compounds with antiviral activity. Coupled to the use of automated plate readers, these recombinant viruses can make antiviral assays more suitable for standardization and high-throughput purposes (Rameix-Welti et al., 2014). Recently, recombinant viruses expressing luciferase have been developed and used for screening of antiviral agents against several viruses including human cytomegalovirus (Song et al., 2000; He et al., 2011), dengue virus (Zou et al., 2011), Ebola virus (Hoenen et al., 2013), Nipah virus (Lo et al., 2014), respiratory syncytial virus (Rameix-Welti et al., 2014), classical swine fever virus (Shen et al., 2014) and influenza A virus (Li et al., 2018). Luciferase-based methods can also be used for the study of viral gene expression (Song et al., 2000), the non-invasive and continuous monitoring of systemic infection in vivo and the exploring virus-host interactions (Barry et al., 2012). A bioluminescence imaging system was also introduced to monitor MHV-68 infection in the whole mouse (Hwang et al., 2008; Milho et al., 2009; Lee et al., 2011; Kang et al., 2012).

At many institutes of chemistry, novel compounds with potential biological activity such as quinolone derivatives are synthesized. Quinolones represent an important class of broad-spectrum antibacterial agents. Recently, quinolones have been reported to possess a variety of useful biological activities, including antitumor, antiparasitic, antifungal, and antiviral activities (Richter et al., 2004; Ahmed and Daneshtalab, 2012; Dalhoff, 2015).

The aim of this study was to establish a rapid and sensitive method for testing potential antiviral compounds against gammaherpesviruses by use of a luciferase-expressing MHV-68. This novel optimized assay, termed luciferase activity reduction assay, was compared with conventional plaque reduction assay and its reliability was verified. Furthermore, in an attempt to identify novel inhibitors of gammaherpesvirus replication, newly synthesized quinolone/quinoline derivatives were screened for their antiviral activity using luciferase activity reduction assay.

\section{Materials and Methods}

Cells. African green monkey kidney (Vero) cells were cultured in complete Dulbecco's modified Eagle's medium (DMEM) containing 9\% heat-inactivated fetal bovine serum (FBS) and supplemented with L-glutamine ( $2 \mathrm{mM}$ ), penicillin (100 units $/ \mathrm{ml}$ ) and streptomy$\operatorname{cin}(100 \mu \mathrm{g} / \mathrm{ml})$. Cell cultures were grown in a $5 \% \mathrm{CO}_{2}$ humidified atmosphere at $37^{\circ} \mathrm{C}$.

Viruses. Working MHV-68 stock (isolated from Myodes glareolus, Blaškovič et al., 1980) was prepared by infection of Vero cells at low multiplicity of infection (MOI). Recombinant MHV-68 expressing firefly luciferase (MHV-68/LUC) was constructed as previously described (Hwang et al., 2008). Viral titers were determined by plaque assay using Vero cells.

Compounds. The 2-(1-glycosyl-1,2,3-triazol-4-yl)-3-hydroxyquinolone conjugates (Table 1) used in this study were synthesized according to the previously reported procedure (Šamšulová et al., 2019). Stock solutions $(2 \mathrm{mg} / \mathrm{ml})$ were prepared by dissolving compounds in dimethyl sulfoxide (DMSO), filtered through a $0.2 \mu \mathrm{m}$ filter and diluted to the appropriate concentrations in culture media. Acyclovir (ACV; Sigma-Aldrich) and ganciclovir (GCV; Sigma-Aldrich) were dissolved in distilled water to the concentration of $1 \mathrm{mg} / \mathrm{ml}$.

Growth curves. Multistep virus growth curves were obtained by infecting subconfluent Vero cells at a MOI of 0.01. After adsorption for 1 hour, the wells were washed with medium to remove residual virus and fresh DMEM containing $2 \%$ FBS was added. At various times post infection, the cells and supernatants were harvested, 
Table 1. List of tested compounds

\begin{tabular}{|c|c|}
\hline Compound & Systematic name for compound \\
\hline Q1 & 2-(1-( $\beta$-D-Ribofuranosyl)-1,2,3-triazol-4-yl)-3,4-methylenedioxy-quinoline \\
\hline Q2 & 2-(1-( $\beta$-D-Ribofuranosyl)-1,2,3-triazol-4-yl)-3,4-dibenzyloxy-quinoline \\
\hline Q3 & 2-(1-( $\beta$-D-Ribofuranosyl)-1,2,3-triazol-4-yl)-3-hydroxyquinolin-4-one \\
\hline Q4 & 2-(1-( $\beta$-D-Xylopyranosyl)-1,2,3-triazol-4-yl)-3,4-dibenzyloxy-quinoline \\
\hline Q5 & 2-(1-( $\beta$-D-Xylopyranosyl)-1,2,3-triazol-4-yl)-3-hydroxyquinolin-4-one \\
\hline Q6 & 2-(1-( $\beta$-D-Glucopyranosyl)-1,2,3-triazol-4-yl)-3,4-methylenedioxy-quinoline \\
\hline Q7 & 4-ethynyl-[1,3]dioxolo[4,5-c]quinoline \\
\hline Q8 & 3,4-bis(benzyloxy)-2-ethynylquinoline \\
\hline
\end{tabular}

frozen and thawed three times, and subjected to plaque assays on Vero cells. All experiments were carried out in duplicate.

Cytotoxicity assays. The cytotoxicity of tested compounds was assessed via the 3-(4,5-dimethylthiazol-2-yl)-2,5-diphenyltetrazolium bromide (MTT) assay and the lactate dehydrogenase (LDH) assay. Vero cells were seeded at $1 \times 10^{4}$ cells per well in DMEM containing 9\% FBS into 96-well tissue culture plates. After a $24 \mathrm{~h}$ period of incubation, the culture medium was removed and replenished with $150 \mu \mathrm{l}$ of DMEM containing 2\% FBS and various concentrations of the tested compounds (in duplicate). At final dilutions, the concentration of DMSO never exceeded $0.5 \%$. Solvent controls were run simultaneously - these wells were set to represent $100 \%$ of viability in MTT assay and the level of spontaneous LDH release from cells. The maximal LDH release was established by cell lysis with $1 \%$ Triton X-100. Cells not treated with compounds or DMSO were used as control cells. Cells were then incubated for 2 days in a $5 \% \mathrm{CO}_{2}$ humidified atmosphere at $37^{\circ} \mathrm{C}$. After treatment, $50 \mu \mathrm{l}$ of supernatant were carefully removed from each well without disturbing the cells and transferred into corresponding wells of another 96-well plate - this plate was immediately used for $\mathrm{LDH}$ assay. The original plate containing cells with $100 \mu$ l of supernatant per well was used for MTT assay. MTT assay: Then, $10 \mu$ of MTT solution $(5 \mu \mathrm{g} / \mathrm{ml}$ in PBS) was added to each well and the plate was wrapped with aluminium foil and incubated for $2 \mathrm{~h}$ at $37^{\circ} \mathrm{C}$. After this incubation, the mixture was removed and $100 \mu \mathrm{l}$ of DMSO was added to each well to dissolve formazan crystals. After gently shaking the plate for $20 \mathrm{~min}$, the absorbance was measured on the Epoch ${ }^{\mathrm{Tx}}$ Microplate Spectrophotometer (Biotek) at a test wavelength of $570 \mathrm{~nm}$ with a reference wavelength of $690 \mathrm{~nm}$. The percentage of cell viability was calculated as [(compound treated sample) / (solvent control) $] \times 100$. The $50 \%$ cytotoxic concentration $\left(\mathrm{CC}_{50}\right)$ was defined as the compound concentration $(\mu \mathrm{g} / \mathrm{ml})$ required for the reduction of cell viability by $50 \%$ when compared to the solvent controls. The $\mathrm{CC}_{50}$ values of each compound were calculated as the mean from two independent experiments using Prism 7 (GraphPad Software Inc.). LDH assay: The LDH assay reagent was freshly prepared according to the published protocol (Kaja et al., 2015). Then, $50 \mu \mathrm{l}$ of assay reagent were added to each well of plate containing $50 \mu$ of supernatant and mixed briefly on an orbital shaker. The plate was then incubated at room temperature in the dark for $1 \mathrm{~h}$. After this incubation, $50 \mu \mathrm{l}$ of $1 \mathrm{M}$ acetic acid were added to each well to stop the reaction and stabilize the product. The absorbance was measured on the Epoch ${ }^{\text {ix }}$ Microplate Spectrophotometer (Biotek) at a test wavelength of $490 \mathrm{~nm}$ with a reference wavelength of $650 \mathrm{~nm}$. The percentage of cytotoxicity was calculated as [(compound treated sample - solvent control) / (maximum LDH release control - solvent control)] $\times 100$.

Plaque reduction assay. Vero cells were seeded in 24-well tissue culture plates at $1.5 \times 10^{4}$ cells per well. Next day, the cells were infected with a viral inoculum of approximately $50 \mathrm{PFU} /$ well. After 90 min of incubation at $37^{\circ} \mathrm{C}$, residual viral particles were removed, and the wells were overlaid with $1 \mathrm{ml}$ of $1 \%$ carboxymethylcellulose in normal growth media containing serial dilutions of the tested compounds (in duplicate). Solvent treatment was served as a negative control, while GCV $(10 \mu \mathrm{g} / \mathrm{ml})$ was used as a positive control. After 6 days of incubation at $37^{\circ} \mathrm{C}$ and $5 \% \mathrm{CO}_{2}$, monolayers were fixed and stained with $0.2 \%$ crystal violet in $20 \%$ ethanol. The plaques were then counted microscopically. The $50 \%$ inhibitory concentration $\left(\mathrm{IC}_{50}\right)$ was defined as the compound concentration $(\mu \mathrm{g} / \mathrm{ml})$ required to reduce the plaque number by $50 \%$ when compared to the negative control wells. The $\mathrm{IC}_{50}$ values of each compound were calculated as the mean from two independent experiments using Prism 7 (GraphPad Software Inc.).

Luciferase activity reduction assay. Vero cells were seeded at $2 \times 10^{4}$ cells per well in 96-well plate. After incubation overnight, the cells were infected with MHV-68/LUC at a MOI of 0.05. After $90 \mathrm{~min}$ adsorption at $37^{\circ} \mathrm{C}$, the virus inoculum was removed, and $100 \mu \mathrm{l}$ of DMEM containing 2\% FBS and noncytotoxic concentrations of the tested compounds (in duplicate) were added to each well. The infected cells treated with solvent were included as a negative control, while the infected cells with ACV $(10 \mu \mathrm{g} / \mathrm{ml})$ or GCV $(10 \mu \mathrm{g} / \mathrm{ml})$ were used as positive controls. After 2 days of incubation at $37^{\circ} \mathrm{C}$ and $5 \% \mathrm{CO}_{2}$, the plate was subjected to three freeze-thaw cycles to achieve complete cell lysis and centrifuged at $1000 \times \mathrm{g}$ for $10 \mathrm{~min}$ at $4^{\circ} \mathrm{C}$. Then, $50 \mu \mathrm{l}$ of the supernatant were transferred into corresponding wells of a white opaque 96 -well plate. Firefly luciferase assay reagent $(2 x)$ was prepared fresh before each use according to the previously published pro- 
(a)

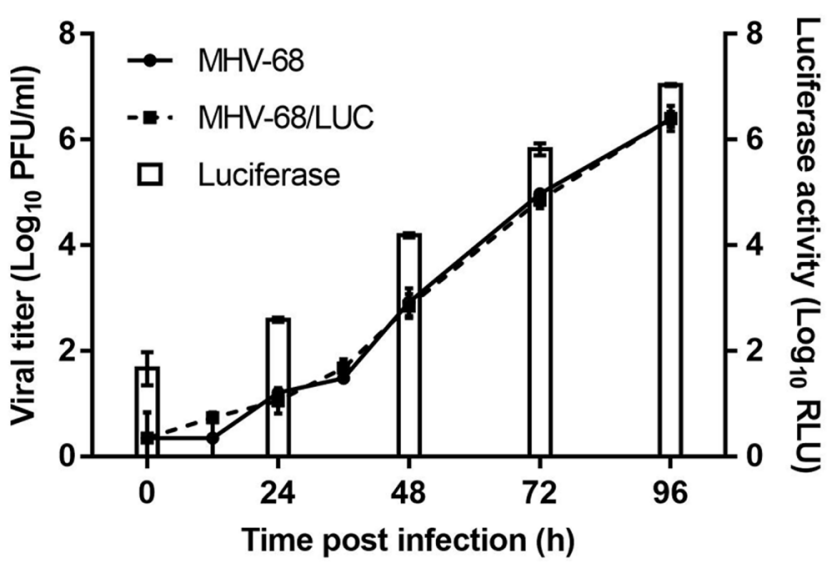

(c)

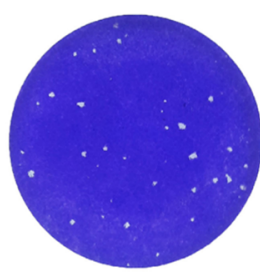

MHV-68 (b)

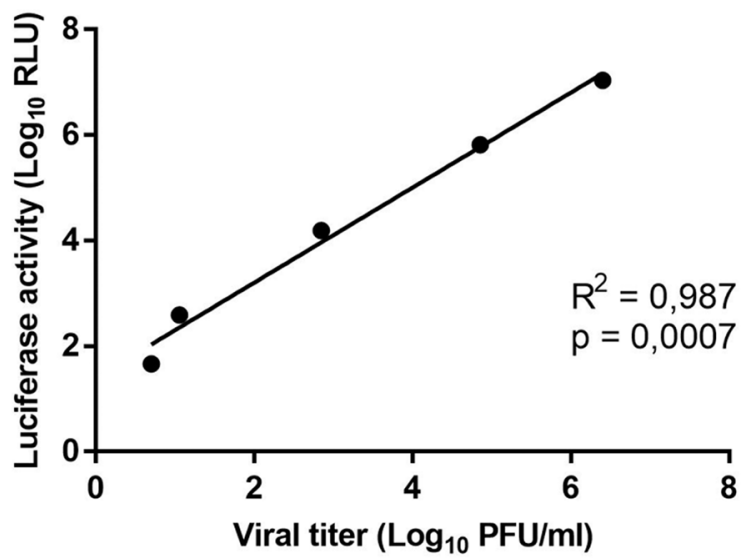

Fig. 1

Growth properties of recombinant MHV-68/LUC

(a) Multistep growth curves of MHV-68/LUC and MHV-68. Vero cells were infected at a MOI of 0.01 and incubated at $37^{\circ} \mathrm{C}$. At the indicated time points, the cells and supernatants were collected and viral titers were determined by performing a plaque assay. Reporter activity level on day 0 post infection indicates background noise of the luminometer. (b) Linear correlation between MHV-68/LUC titers and luciferase activity (expressed as relative light units, $\mathrm{RLU})$. Linear regression curve and coefficient of determination $\left(\mathrm{R}^{2}\right)$ are shown. (c) Plaque morphology of the wild type virus and the recombinant virus.

tocol (Oba et al., 2003) with minor modifications - it contained $300 \mu \mathrm{g} / \mathrm{ml} \mathrm{D}$-Luciferin, $300 \mu \mathrm{M}$ ATP, $500 \mu \mathrm{M}$ coenzyme A and $10 \mathrm{mM} \mathrm{MgCl}$ in $200 \mathrm{mM}$ Tris- $\mathrm{HCl} \mathrm{pH}$ 7.8. Luciferase activity was measured using Synergy ${ }^{\mathrm{Tm}}$ H4 Hybrid Multi-Mode Microplate Reader (Biotek) with injector. Injection volume was $50 \mu \mathrm{l}$ per well. Signal integration was for $10 \mathrm{~s}$ with delay settings of $2 \mathrm{~s}$ after each injection. The $\mathrm{IC}_{50}$ value was defined as the compound concentration $(\mu \mathrm{g} / \mathrm{ml})$ required to reduce the luminescence signal by $50 \%$ when compared to the negative control wells. In order to demonstrate the reproducibility of the luciferase activity reduction assay, a series of at least two independent experiments were performed and the $\mathrm{IC}_{50}$ values of each compound were calculated as the mean from these independent experiments using Prism 7 (GraphPad Software Inc.).

Statistical analysis. The results were processed using the software Prism 7 (GraphPad Software Inc.). All data were expressed as mean \pm standard deviation (SD). To describe the cytotoxicity, cell viability and antiviral activity, one-way analysis of variance (ANOVA) with Dunnett's post hoc test was used.

\section{Results and Discussion}

Growth properties of recombinant virus in Vero cells

To establish a novel screening system for antiviral activity against gammaherpesviruses, a recombinant MHV-68 that expresses the firefly luciferase under the control of the M3 viral promoter (MHV-68/LUC) was used. The M3 promoter is highly responsive to the replication and transcription activator (Rta) (Martinez-Guzman et al., 2003). The Rta protein encoded by ORF50 of MHV-68 transactivates viral gene expression, triggering the lytic replication cycle (Liu et al., 2000). M3 transcripts are abundantly expressed during lytic replication of MHV-68 in vitro (Martinez-Guzman et al., 2003). Thus, the infection of cells with MHV-68/LUC enables quantitation of viral replication by determining the luciferase activity in a luminometer (Hwang et al., 2008).

MHV-68/LUC was constructed by inserting the M3 promoter-driven luciferase expression cassette at the left end 
(a)

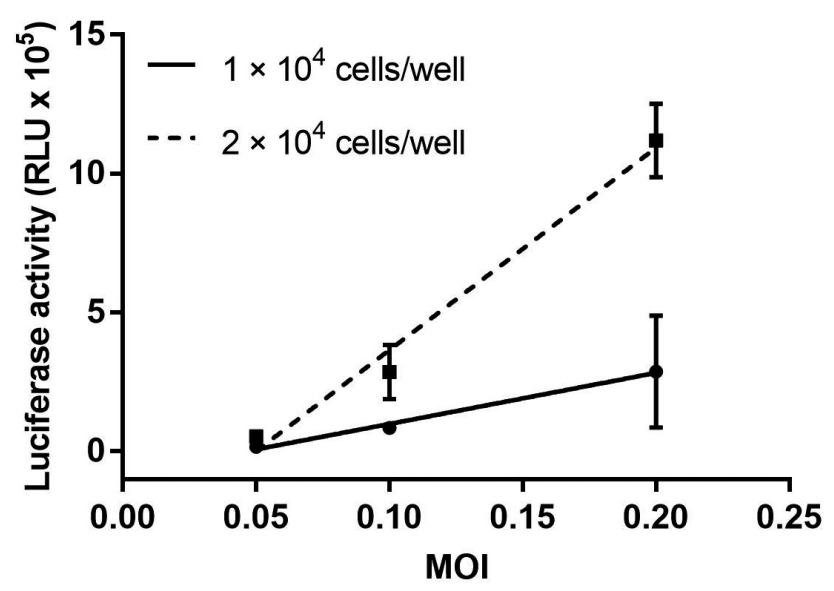

(b)

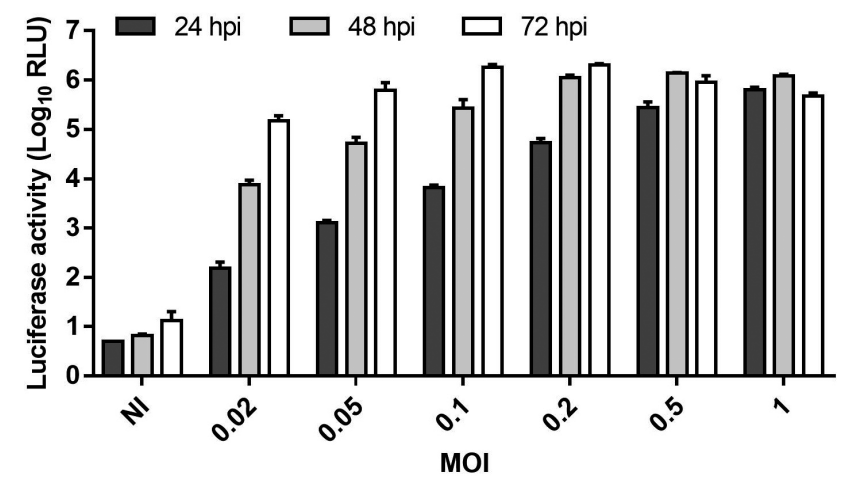

Fig. 2

Optimization of the MHV-68/LUC infection conditions for the novel assay

(a) Correlation between luminescent signal and seeding cell density. Vero cells $\left(1 \times 10^{4}\right.$ or $2 \times 10^{4}$ cells/well $)$ were infected with MHV-68/LUC at indicated MOIs and luciferase activity in relative light units (RLU) was measured $48 \mathrm{~h}$ post infection. Data represent the mean \pm SD of two independent experiments, each performed in triplicate. (b) Correlation between luminescent signal and multiplicity of infection (MOI) at different times post infection. Vero cells were infected with MHV-68/LUC at varying MOIs and luciferase activity in relative light units (RLU) was measured at 24, 48 and 72 hpi. Reporter activity levels in non-infected cells (NI) indicate background noise of the luminometer. Data represent the mean \pm SD of two independent experiments, each performed in triplicate.

of the viral genome according to the previously described procedure (Hwang et al., 2008). Multistep growth curve experiments were conducted to compare the growth kinetics of the recombinant virus with the wild-type virus (Fig. 1). The growth of the recombinant virus in Vero cells was also monitored under a light microscope and typical CPE was observed. The replication kinetics of MHV-68/LUC and MHV-68 were nearly identical (Fig. 1a) and viruses produced plaques of similar sizes (Fig. 1c). In addition, the samples collected during the growth curve of MHV-68/LUC were also used to determine the activity of the expressed firefly luciferase. A direct relationship between luciferase activity and viral titers of MHV-68/LUC measured by a plaque assay was confirmed by regression analysis (Fig. 1b), demonstrating that the luminescent signal can accurately reflect the replication of MHV-68/LUC in vitro.

Optimization of $M H V-68 / L U C$ infection conditions for antiviral screening assay

In order to obtain a sufficiently strong luminescent signal, it was necessary to identify the appropriate conditions for MHV-68/LUC infection in Vero cells. We investigated the optimal seeding cell density, the optimal MOI, and the ideal incubation time for an in vitro antiviral screening assay. Vero cells were seeded in 96-well plates at the density of $1 \times 10^{4}$ or $2 \times 10^{4}$ cells per well. Next day, cells were infected with $\mathrm{MHV}-$ 68/LUC at varying MOIs. At 48 hours post infection (hpi), plates were subjected to three freeze-thaw cycles, centrifuged and the luciferase activity in supernatants was measured. As expected, the luminescence signal positively correlated with the cell number and the virus dose used (Fig. 2a). The cell density of $2 \times 10^{4}$ cells per well was selected for the novel assay. To further optimize the assay, $2 \times 10^{4}$ Vero cells/well were infected with MHV-68/LUC at MOIs ranging from 0.02 to 1 . The infected cells were monitored daily for the development of viral CPE and luciferase activity was measured at 24, 48 and 72 hpi. Luminescent signal correlated well with the increasing MOI and the signal intensity also increased over time post infection (Fig. 2b). In antiviral activity studies, it is advisable to use lower MOIs in order to avoid rapid cell destruction and to enable the detection of the inhibition of virus spread within the cell culture (Marschall et al., 2000; Postnikova et al., 2018). Moreover, the purpose of this study was to develop a rapid assay system for measuring the antiviral activity. Therefore, the optimal experimental conditions were determined as MOI of 0.05 and incubation for $48 \mathrm{~h}$. Under these conditions, the signal-to-noise ratio was high $\left(8.3 \times 10^{3}\right)$ and characteristic viral CPE in Vero cells was observed.

Validation of the luciferase activity reduction assay by known antiherpetic agents

A novel optimized assay was verified using two antiherpetic agents. Since ACV and GCV have been shown to efficiently inhibit the MHV-68 replication in vitro (Sunil- 
(a)

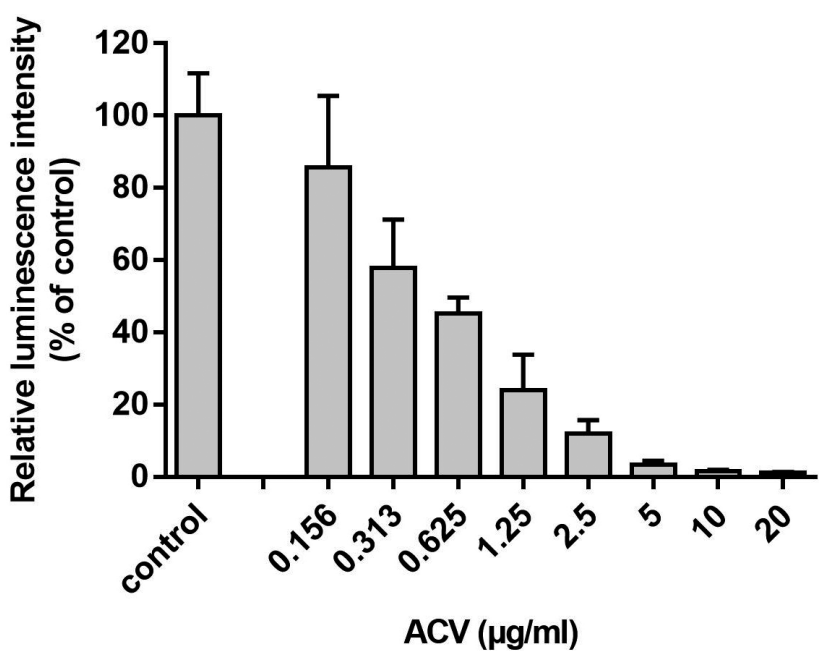

(b)

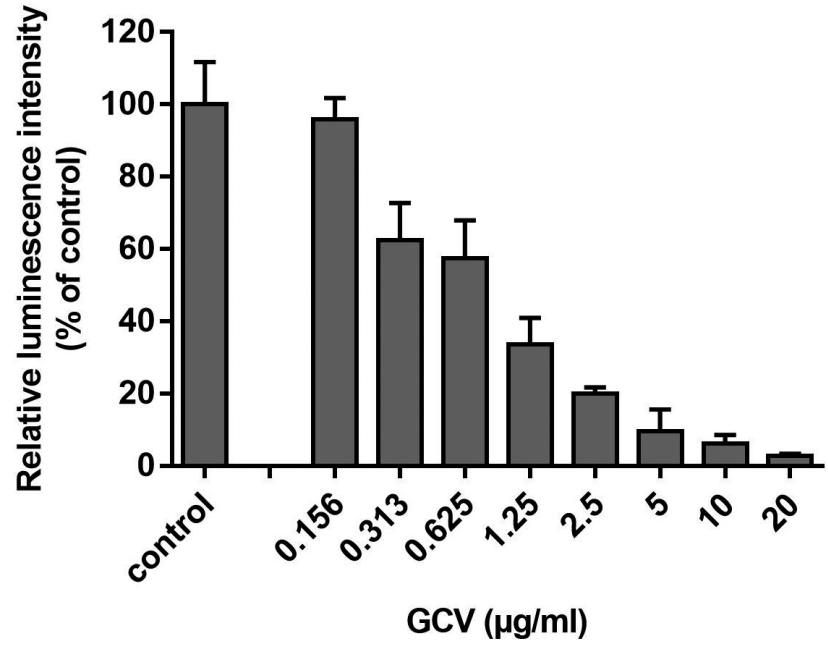

Fig. 3

In vitro antiviral testing using MHV-68/LUC as a tool

Vero cells were infected with MHV-68/LUC at the MOI of 0.05 and the infected cells were incubated in the presence of serial dilutions of (a) acyclovir (ACV) or (b) ganciclovir (GCV) in duplicate. The luciferase activity was measured 48 hpi using an automatic plate luminometer. Solvent-treated infected cells were set to represent $100 \%$ of the luciferase activity (control). The data are normalized to solvent control, and the mean \pm SD for the results of two independent experiments are shown.

Table 2. Cytotoxicity and antiviral activity of selected compounds against MHV-68/LUC in Vero cells.

\begin{tabular}{|c|c|c|c|c|c|}
\hline \multirow{2}{*}{ Compounds } & \multirow{2}{*}{$\begin{array}{c}\text { MTT assay } \\
\mathrm{CC}_{50}(\mu \mathrm{g} / \mathrm{ml})^{\mathrm{a}}\end{array}$} & \multicolumn{2}{|c|}{ Plaque reduction assay } & \multicolumn{2}{|c|}{ Luciferase activity reduction assay } \\
\hline & & $\mathrm{IC}_{50}(\mu \mathrm{g} / \mathrm{ml})^{\mathrm{a}}$ & SI & $\mathrm{IC}_{50}(\mu \mathrm{g} / \mathrm{ml})^{\mathrm{a}}$ & SI \\
\hline Acyclovir & $>250$ & $1.431 \pm 0.097$ & $>175$ & $0.493 \pm 0.041$ & $>507$ \\
\hline Ganciclovir & $>250$ & $2.798 \pm 0.316$ & $>89$ & $0.724 \pm 0.056$ & $>345$ \\
\hline Q4 & $19.12 \pm 0.954$ & $4.875 \pm 0.594$ & 4 & $1.760 \pm 0.321$ & 11 \\
\hline
\end{tabular}

${ }^{a}$ Values represent the mean $\pm \mathrm{SD}$ of two independent experiments. $\mathrm{CC}_{50}=$ concentration required to reduce cell viability by $50 \%$; $\mathrm{IC}_{50}=$ concentration required to reduce plaque formation or luciferase activity by $50 \%$; $\mathrm{SI}=$ selectivity index (ratio of $\mathrm{CC}_{50} / \mathrm{IC}_{50}$ ).

Chandra et al., 1994; Smee et al., 1997; Neyts and De Clercq, 1998; Coen et al., 2013), these inhibitors were selected for the assay validation. ACV and GCV belong to the group of purine acyclic nucleoside analogues (De Clercq, 2013). A dose-dependent inhibition of the luciferase activity was observed following treatment of the MHV-68/LUC infected Vero cells with serial dilutions of ACV (Fig. 3a) or GCV (Fig. 3b), while no obvious cytotoxicity was detected for either drug at the highest concentrations tested (Table 2). Reduction of luciferase activity in MHV-68/LUC-infected cells treated with the two compounds allowed the determination of $\mathrm{IC}_{50}$ values for both inhibitors. For ACV, the

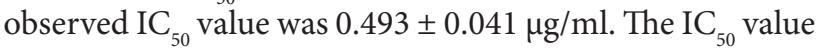
of GCV was $0.724 \pm 0.056 \mu \mathrm{g} / \mathrm{ml}$. Consistent with the previously published studies (Neyts and De Clercq, 1998; Coen et al., 2013), virus was more susceptible to ACV than GCV in vitro. To compare the luciferase activity reduction assay with a conventional method, $\mathrm{IC}_{50}$ values of ACV and GCV were also determined by the plaque reduction assay. The observed $\mathrm{IC}_{50}$ values, $1.431 \pm 0.097$ and $2.798 \pm 0.316 \mu \mathrm{g} / \mathrm{ml}$ for ACV and GCV, respectively, were in the same range as those determined by the novel assay. Table 2 summarizes the $\mathrm{CC}_{50}$ and $\mathrm{IC}_{50}$ values of the inhibitors in these antiviral assays. Slightly lower $\mathrm{IC}_{50}$ values obtained using luciferase activity reduction assay indicate a high sensitivity of the novel assay (Marschall et al., 2000). The variation in $\mathrm{IC}_{50}$ values may possibly be related to the subjective nature of the plaque reduction assay. Moreover, the usage of the classical plaque reduction assay does not take into account the size of plaques. Another disadvantage of the plaque reduction assay is the 
(a)

MTT assay

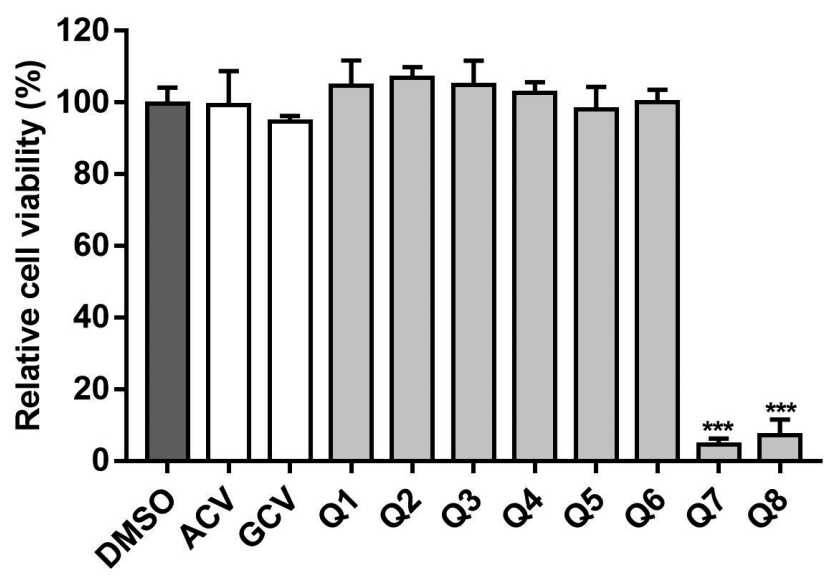

(b)

LDH assay

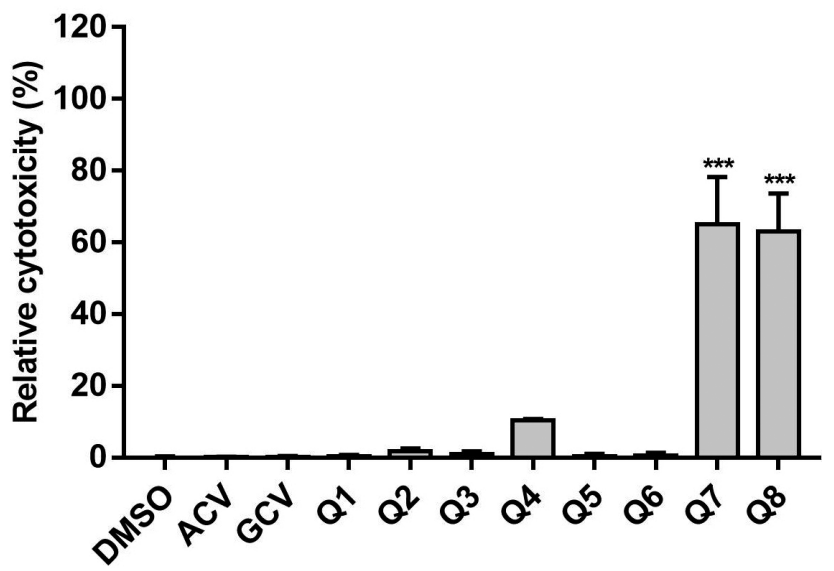

Fig. 4

Cytotoxicity data of novel quinolone/quinoline derivatives in Vero cells

Vero cells were treated with various compounds $(10 \mu \mathrm{g} / \mathrm{ml})$ for $48 \mathrm{~h}$. Relative cell viability was determined by (a) MTT assay, while relative cytotoxicity was determined by (b) LDH assay, as described in Materials and Methods. Data are presented as mean \pm SD of two independent experiments, each performed in duplicate. Statistical analysis of the data was performed using one-way ANOVA, followed by Dunnett's post hoc test for multiple comparisons. Statistically significant differences between the solvent control (DMSO) and the treatment groups are indicated by asterisks: ${ }^{* * *} \mathrm{P} \leq 0.001$.

impossibility of determining the amount of viral replication within single cell. Not infrequently, the end-point of the test shows enlarged cells without spread of the virus to adjacent cells (He et al., 2011). However, the above shortcomings of plaque reduction assay can be successfully overcome by using the sensitive luciferase-based method. Taken together, our results suggest that the luciferase activity reduction assay is applicable for screening of antiviral compounds against gammaherpesviruses and, importantly, is superior to conventional antiviral screening assays.

Evaluation of the cytotoxicity of newly synthesized quinolone/quinoline derivatives

Effective antiviral compounds should specifically inhibit one or more steps of virus replication without adversely affecting the host cell metabolism (De Clercq, 1982). Therefore, assessment of the cytotoxicity is an important part of the evaluation of a potential antiviral agent. One of the most widely used cytotoxicity or cell proliferation assays is the MTT assay, which is a quantitative colorimetric assay. The assay assesses mitochondrial cellular function based on the enzymatic reduction of the tetrazolium salt MTT by the mitochondrial dehydrogenases in viable cells. Another commonly used assay is the $\mathrm{LDH}$ assay. This colorimetric method is based on measuring the activity of cytoplasmic enzyme LDH released into cell culture medium by damaged or lysed cells (Fotakis and Timbrell, 2006).
In this study, a total of 8 compounds, newly synthesized quinolone/quinoline derivatives (Table 1), were subjected to cytotoxicity assays. Vero cells were incubated in the presence of tested compounds at a single concentration of $10 \mu \mathrm{g} / \mathrm{ml}$, as it was the maximum compound concentration possible to keep final DMSO content non-cytotoxic. After 48 hours of incubation, cell viability was evaluated by MTT assay. Most compounds did not affect the cell viability, while compounds Q7 and Q8 significantly reduced number of viable Vero cells (Fig. 4a). In order to determine if the reduction in cell viability obtained with MTT assay was due to cytotoxicity or antiproliferative activity, the $\mathrm{LDH}$ assay was also performed. High accumulation of $\mathrm{LDH}$ in media was observed after treatment of Vero cells with compounds Q7 and Q8, demonstrating the significant cytotoxic effects of these compounds (Fig. 4b). Therefore, we did not include these cytotoxic compounds in further experiments.

Evaluation of antiviral activity of newly synthesized quinolone/quinoline derivatives against $M H V-68$ in vitro

The effect of noncytotoxic compounds on the gammaherpesvirus replication in vitro was examined using luciferase activity reduction assay. Vero cells were treated with $10 \mu \mathrm{g} / \mathrm{ml}$ of compounds after infection with MHV-68/LUC at a MOI of 0.05 . DMSO treatment was served as a negative control, while ACV and GCV were included as positive controls. Luciferase activity was measured at 48 hpi. Compound Q4 (Fig. 5) 


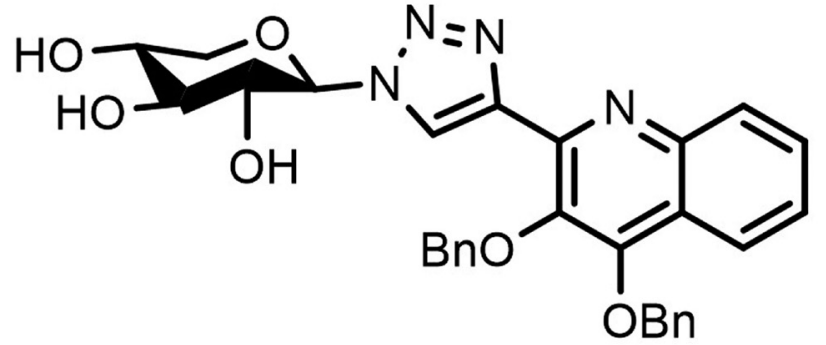

Fig. 5

Chemical structure of compound Q4

2-(1-( $\beta$-D-Xylopyranosyl)-1,2,3-triazol-4-yl)-3,4-dibenzyloxy-quinoline.

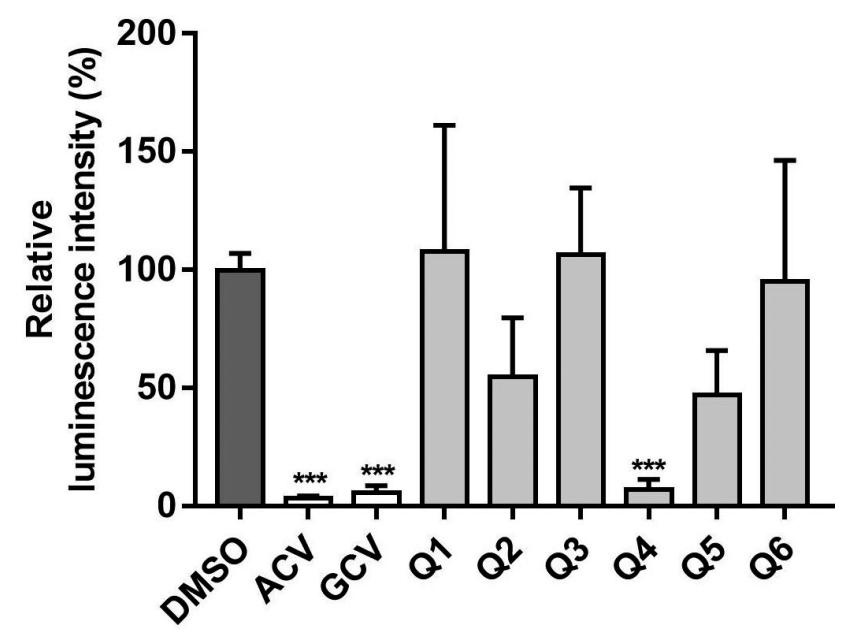

Fig. 6

Screening of novel quinolone/quinoline derivatives for antiviral activity against MHV-68/LUC

The compounds were screened for antiviral activity using luciferase activity reduction assay, as described in Materials and Methods. Briefly, Vero cells were infected with MHV-68/LUC at the MOI of 0.05 and infected cells were treated with various compounds at the concentration of $10 \mu \mathrm{g} / \mathrm{ml}$ After $48 \mathrm{~h}$ of incubation, luciferase activity was measured. Values were then normalized to solvent control (DMSO). Data are presented as mean \pm SD of three independent experiments, each performed in duplicate. Statistical analysis of the data was performed using one-way ANOVA, followed by Dunnett's post hoc test for multiple comparisons. Statistically significant differences between the solvent control (DMSO) and the treatment groups are indicated by asterisks: ${ }^{* *} \mathrm{P} \leq 0.001$.

was consistently identified with significant antiviral activity against MHV-68/LUC from three independent screenings (Fig. 6). To quantify the antiviral effect, the inhibition rates of compound Q4 at different concentrations were determined and $\mathrm{IC}_{50}$ value was calculated using nonlinear regression analysis. The inhibitory effect of compound Q4 showed dosedependent pattern (Fig. 7). The $\mathrm{IC}_{50}$ of compound $\mathrm{Q} 4$ against MHV-68/LUC was estimated to be $1.760 \pm 0.321 \mu \mathrm{g} / \mathrm{ml}$.

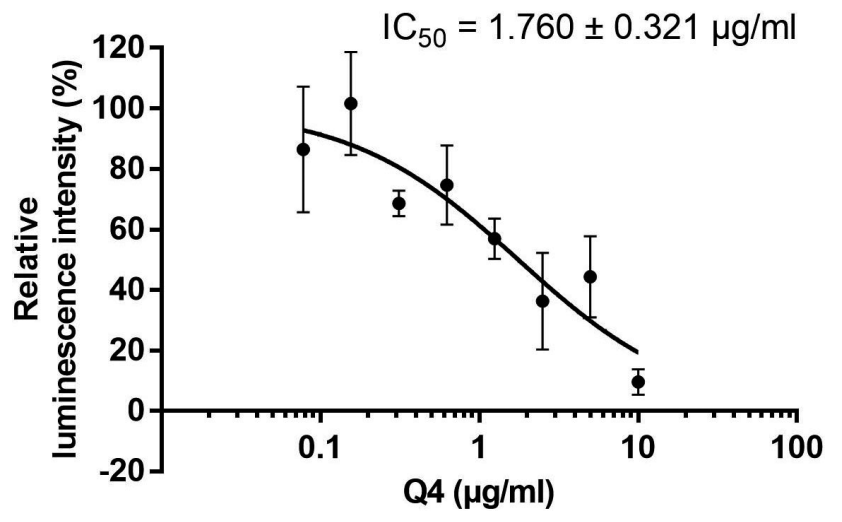

Fig. 7

A dose-response curve for compound Q4

The antiviral activity of the compound Q4 against MHV-68/LUC was determined by luciferase activity reduction assay, as described in Materials and Methods. Briefly, Vero cells were incubated with increasing amounts of compound Q4 ranging from $0.078 \mu \mathrm{g} / \mathrm{ml}$ to $10 \mu \mathrm{g} / \mathrm{ml}$ after MHV-68/ LUC infection. After $48 \mathrm{~h}$ of incubation, luciferase activity was measured. Relative levels of luminescence intensity were calculated as a percentage of levels in solvent-treated infected cells. Data are presented as mean \pm SD of two independent experiments, each performed in duplicate. The $\mathrm{IC}_{50}$ value was defined as the concentration of compound Q4 required to reduce luciferase activity by $50 \%$.

In some cases, newly synthesized compounds can quench the luminescence without inhibiting viral replication (Zhang et al., 2016). Therefore, after the initial screening of novel compounds using the luciferase activity reduction assay and identification of active compounds, it is recommended to confirm the antiviral activity of identified compounds using a second assay.

In addition to luciferase activity reduction assay, compound Q4 was also tested in the plaque reduction assay. MHV-68 infected cells were treated with serial dilutions of the compound Q4 for 6 days. Compound Q4 reduced the plaque number and the plaque size in the dose-dependent manner (Fig. 8). The $\mathrm{IC}_{50}$ value for compound Q4 obtained with plaque reduction assay was within 3 -fold of the $\mathrm{IC}_{50}$ value determined by luciferase activity reduction assay (Table 2), indicating that MHV-68/LUC can serve as antiviral screening tool.

Taken together, these results demonstrate that compound Q4 has strong antiviral activity against MHV-68 in vitro. Compound Q4 also exhibited inhibitory effect against Grampositive bacterial strains (Šamšulová et al., 2019). It seems that combining di-O-benzyl protected quinoline (compound Q8) with xylosyl moiety led to the loss of cytotoxic activity of the compound and to the improvement of its antibacterial and antiviral effects. Therefore, a novel synthetic route to 2-substituted-3-hydroxyquinolone conjugates paves the way for extending the range of new biologically active derivatives (Šamšulová et al., 2019). 

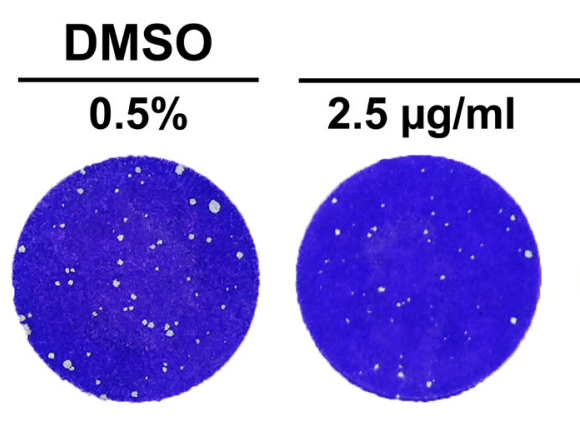

\section{Q4}

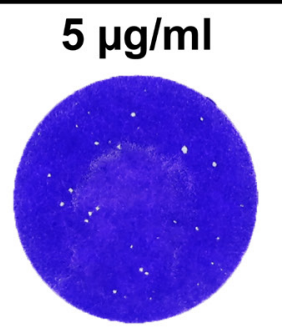

GCV

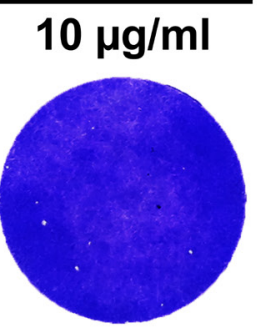

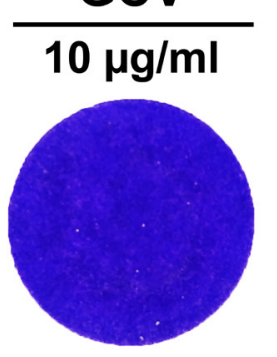

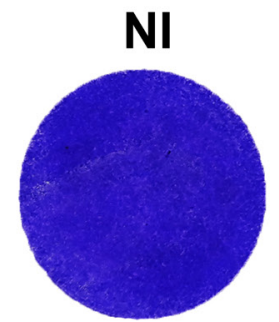

Fig. 8

Plaque reduction assay of compound Q4 against MHV-68

Vero cells were infected with MHV-68 (50 PFU/well) and infected cells were covered with overlay media containing serial two-fold dilutions of compound Q4. Solvent treatment (DMSO) served as a negative control, while ganciclovir (GCV) was used as a positive control. Non-infected cells (NI) incubated with overlay media alone were used as control cells. After 6 days of incubation, plaques were visualized by crystal violet staining.

\section{Determination of selectivity index of compound Q4}

The potency of antiviral agents is estimated by the ratio of $\mathrm{CC}_{50}$ and $\mathrm{IC}_{50}$. This relationship is called in vitro selectivity index (SI). The SI value of an antiviral agent must be at least in the range of 100 to 1000 to indicate useful effect on viral inhibition in animal experiments (Omura, 1992). The compound Q4 was found to have low SI value (Table 2), thus it was not suitable for in vivo testing in animal model.

\section{Conclusion}

A novel antiviral screening assay for identifying compounds with activity against gammaherpesviruses has been developed. The luciferase activity reduction assay yielded similar data as the plaque assay, but its performance, especially the rapidity, was superior. Moreover, measurements using automated microplate luminometer are objective, quick and conducive to handling large number of plates during screening.

Acknowledgments. The authors thank prof. Ren Sun for donating plasmids and Escherichia coli strains for recombinant virus construction and Dr. Anna Kostrábová for contributing helpful ideas. This work was supported by the Scientific Grant Agency of Ministry of Education of Slovak Republic and Slovak Academy of Sciences (project VEGA No. 1/0617/15) and Development of novel synthetic methods for preparation of novel biological active compounds (project IGA_PrF_2018_29).

\section{References}

Ahmed A, Daneshtalab M (2012): Nonclassical biological activities of quinolone derivatives. J. Pharm. Pharm. Sci. 15, 52-72. https://doi.org/10.18433//3302N
Barnes A, Dyson H, Sunil-Chandra NP, Collins P, Nash AA (1999): 2'-deoxy-5-ethyl-beta-4'-thiouridine inhibits replication of murine gammaherpesvirus and delays the onset of virus latency. Antivir. Chem. Chemother. 10, 321-326. https://doi.org/10.1177/095632029901000603

Barry MA, May S, Weaver EA (2012): Imaging luciferase-expressing viruses. Methods Mol. Biol. 797, 79-87. https://doi. org/10.1007/978-1-61779-340-0 6

Blaškovič D, Stančeková M, Svobodová J, Mistríková J (1980): Isolation of five strains of herpesviruses from two species of free living small rodents. Acta Virol. 24, 468.

Cesarman E (2014): Gammaherpesviruses and lymphoproliferative disorders. Annu. Rev. Pathol. 9, 349-372. https://doi. org/10.1146/annurev-pathol-012513-104656

Cho HJ, Jeong SG, Park JE, Han JA, Kang HR, Lee D, Song MJ (2013): Antiviral activity of angelicin against gammaherpesviruses. Antiviral Res. 100, 75-83. https://doi. org/10.1016/j.antiviral.2013.07.009

Coen N, Duraffour S, Snoeck R, Andrei G (2014): KSHV Targeted Therapy: An Update on Inhibitors of Viral Lytic Replication. Viruses 6, 4731-4759. https://doi.org/10.3390/ v6114731

Coen N, Singh U, Vuyyuru V, Van Den Oord JJ, Balzarini J, Duraffour S, Snoeck R, Cheng YC, Chu CK, Andrei G (2013): Activity and Mechanism of Action of HDVD, a Novel Pyrimidine Nucleoside Derivative with High Levels of Selectivity and Potency against Gammaherpesviruses. J. Virol. 87, 3839-3851. https://doi.org/10.1128/JVI.03338-12

Dalhoff A (2015): Antiviral, antifungal, and antiparasitic activities of fluoroquinolones optimized for treatment of bacterial infections: a puzzling paradox or a logical consequence of their mode of action? Eur. J. Clin. Microbiol. Infect. Dis. 34, 661-668. https://doi.org/10.1007/s10096-014-2296-3

De Clercq E (1982): Specific targets for antiviral drugs. Biochem. J. 205, 1-13. https://doi.org/10.1042/bj2050001

De Clercq E (2013): Selective anti-herpesvirus agents. Antivir. Chem. Chemother. 23, 93-101. https://doi.org/10.3851/ IMP2533 
Dittmer DP, Damania B (2016): Kaposi sarcoma-associated herpesvirus: immunobiology, oncogenesis, and therapy. J. Clin. Invest. 126, 3165-3175. https://doi.org/10.1172/JCI84418

Fotakis G, Timbrell JA (2006): In vitro cytotoxicity assays: comparison of LDH, neutral red, MTT and protein assay in hepatoma cell lines following exposure to cadmium chloride. Toxicol. Lett. 160, 171-177. https://doi. org/10.1016/j.toxlet.2005.07.001

He R, Sandford G, Hayward GS, Burns WH, Posner GH, Forman M, Arav-Boger R (2011): Recombinant luciferase-expressing human cytomegalovirus (CMV) for evaluation of CMV inhibitors. Virol. J. 8, 40-46. https://doi.org/10.1186/1743422X-8-40

Hoenen T, Groseth A, Callison J, Takada A, Feldmann H (2013): A novel Ebola virus expressing luciferase allows for rapid and quantitative testing of antivirals. Antiviral Res. 99, 207-213. https://doi.org/10.1016/j.antiviral.2013.05.017

Hwang S, Wu TT, Tong LM, Kim KS, Martinez-Guzman D, Colantonio AD, Uittenbogaart CH, Sun R (2008): Persistent gammaherpesvirus replication and dynamic interaction with the host in vivo. J. Virol. 82, 12498-12509. https:// doi.org/10.1128/JVI.01152-08

Jha HC, Banerjee S, Robertson ES (2016): The Role of Gammaherpesviruses in Cancer Pathogenesis. Pathogens 5, pii: E18. https://doi.org/10.3390/pathogens5010018

Kaja S, Payne AJ, Singh T, Ghuman JK, Sieck EG, Koulen P (2015): An optimized lactate dehydrogenase release assay for screening of drug candidates in neuroscience. J. Pharmacol. Toxicol. Methods 73, 1-6. https://doi.org/10.1016/j. vascn.2015.02.001

Kang HR, Cho HJ, Kim S, Song IH, Lee TS, Hwang S, Sun R, Song MJ (2012): Persistent infection of a gammaherpesvirus in the central nervous system. Virology 423, 23-29. https:// doi.org/10.1016/j.virol.2011.11.012

Kang S, Im K, Kim G, Min H (2017): Antiviral activity of 20(R)ginsenoside Rh2 against murine gammaherpesvirus. J. Ginseng Res. 41, 496-502. https://doi.org/10.1016/j. jgr.2016.08.010

Kang S, Song MJ, Min H (2018): Antiviral activity of ginsenoside Rg3 isomers against gammaherpesvirus through inhibition of p38- and JNK-associated pathways. J. Funct. Foods 40, 219-228. https://doi.org/10.1016/j.jff.2017.11.011

Kutok JL, Wang F (2006): Spectrum of Epstein-Barr virus-associated diseases. Annu. Rev. Pathol. 1, 375-404. https://doi. org/10.1146/annurev.pathol.1.110304.100209

Lee S, Salwinski L, Zhang C, Chu D, Sampankanpanich C, Reyes NA, Vangeloff A, Xing F, Li X, Wu TT, Sahasrabudhe S, Deng H, Lacount DJ, Sun R (2011): An integrated approach to elucidate the intra-viral and viral-cellular protein interaction networks of a gamma-herpesvirus. PLoS Pathog. 7, e1002297. https://doi.org/10.1371/journal.ppat.1002297

Li P, Cui Q, Wang L, Zhao X, Zhang Y, Manicassamy B, Yang Y, Rong L, Du R (2018): A Simple and Robust Approach for Evaluation of Antivirals Using a Recombinant Influenza Virus Expressing Gaussia Luciferase. Viruses 10, pii:E325. https://doi.org/10.3390/v10060325
Liu S, Pavlova IV, Virgin HW, Speck SH (2000): Characterization of gammaherpesvirus 68 gene 50 transcription. J. Virol. 74, 2029-2037. https://doi.org/10.1128/JVI.74.4.20292037.2000

Lo MK, Nichol ST, Spiropoulou CF (2014): Evaluation of luciferase and GFP-expressing Nipah viruses for rapid quantitative antiviral screening. Antiviral Res. 106, 53-60. https://doi. org/10.1016/j.antiviral.2014.03.011

Marschall M, Freitag M, Weiler S, Sorg G, Stamminger T (2000): Recombinant Green Fluorescent Protein-Expressing Human Cytomegalovirus as a Tool for Screening Antiviral Agents. Antimicrob. Agents Chemother. 44, 1588-1597. https://doi.org/10.1128/AAC.44.6.1588-1597.2000

Martinez-Guzman D, Rickabaugh T, Wu TT, Brown H, Cole S, Song MJ, Tong L, Sun R (2003): Transcription program of murine gammaherpesvirus 68. J. Virol. 77, 10488-10503. https://doi.org/10.1128/JVI.77.19.10488-10503.2003

Medveczky MM, Sherwood TA, Klein TW, Friedman H, Medveczky PG (2004): Delta-9 tetrahydrocannabinol (THC) inhibits lytic replication of gamma oncogenic herpesviruses in vitro. BMC Medicine 2, 34. https://doi.org/10.1186/1741$\underline{7015-2-34}$

Milho R, Smith CM, Marques S, Alenquer M, May JS, Gillet L, Gaspar M, Efstathiou S, Simas JP, Stevenson PG (2009): In vivo imaging of murid herpesvirus-4 infection. J. Gen. Virol. 90, 21-32. https://doi.org/10.1099/vir.0.006569-0

Mistríková J, Rašlová H, Mrmusová M, Kúdelová M (2000): A murine gammaherpesvirus. Acta Virol. 44, 211-226.

Neyts J, De Clercq E (1998): In vitro and in vivo inhibition of murine gamma herpesvirus 68 replication by selected antiviral agents. Antimicrob. Agents Chemother. 42, 170-172. https://doi.org/10.1128/AAC.42.1.170

Oba Y, Ojika M, Inouye S (2003): Firefly luciferase is a bifunctional enzyme: ATP-dependent monooxygenase and a long chain fatty acyl-CoA synthetase. FEBS Lett. 540, 251-254. https://doi.org/10.1016/S0014-5793(03)00272-2

Odumade OA, Hogquist KA, Balfour HH (2011): Progress and problems in understanding and managing primary Epstein-Barr virus infections. Clin. Microbiol. Rev. 24, 193-209. https://doi.org/10.1128/CMR.00044-10

Omura S (1992): The Search for Bioactive Compounds from Microorganisms. Springer, New York, 354 pp. https://doi. org/10.1007/978-1-4612-4412-7

Pagano JS (1999): Epstein-Barr virus: the first human tumor virus and its role in cancer. Proc Assoc. Am. Physicians 111, 573-580. https://doi.org/10.1046/j.1525-1381.1999.t01$\underline{1-99220 . x}$

Pagano JS, Whitehurst CB, Andrei G (2018): Antiviral Drugs for EBV. Cancers (Basel) 10, pii: E197. https://doi. org/10.3390/cancers10060197

Pellett PE, Roizman B (2013). Herpesviridae. In Knipe DM, Howley PM (Eds): Fields Virology. 6th ed. Lippincott Williams \& Wilkins : Philadelphia, pp. 1802-1822.

Postnikova E, Cong Y, DeWald LE, Dyall J, Yu S, Hart BJ, Zhou H, Gross R, Logue J, Cai Y, Deiuliis N, Michelotti J, Honko AN, Bennett RS, Holbrook MR, Olinger GG, Hensley LE, Jahrling PB (2018): Testing therapeutics in cell-based assays: Factors that influence the apparent potency of 
drugs. PLoS One. 13, e0194880. https://doi.org/10.1371/ journal.pone. 0194880

Rameix-Welti MA, Le Goffic R, Hervé PL, Sourimant J, Rémot A, Riffault S, Yu Q, Galloux M, Gault E, Eléouët JF (2014): Visualizing the replication of respiratory syncytial virus in cells and in living mice. Nat. Commun. 5, 5104. https:// doi.org/10.1038/ncomms6104

Richter S, Parolin C, Palumbo M, Palù G (2004): Antiviral properties of quinolone-based drugs. Curr Drug Targets Infect. Disord. 4, 111-116. https://doi.org/10.2174/15680050 $\underline{43340920}$

Šamšulová V, Poláková M, Horák R, Šedivá M, Kvapil L, Hradil P (2019): Synthetic approach to novel glycosyltriazole3-hydroxyquinolone conjugates and their antimicrobial properties. J. Mol. Struct. 1177, 16-25. https://doi. org/10.1016/j.molstruc.2018.09.030

Shen L, Li Y, Chen J, Li C, Huang J, Luo Y, Sun Y, Li S, Qiu HJ (2014): Generation of a recombinant classical swine fever virus stably expressing the firefly luciferase gene for quantitative antiviral assay. Antiviral Res. 109, 15-21. https://doi. org/10.1016/j.antiviral.2014.06.006

Simas JP, Efstathiou S (1998): Murine gammaherpesvirus 68: a model for the study of gammaherpesvirus pathogenesis. Trends Microbiol. 6, 276-282. https://doi.org/10.1016/ $\underline{\text { S0966-842X(98)01306-7 }}$
Smee DF, Burger RA, Warren RP, Bailey KW, Sidwell RW (1997): An immunosuppressed mouse model of lethal murine gammaherpesvirus 68 infection for studying potential treatment of Epstein-Barr virus infection in man. Antivir Chem Chemother. 8, 573-581. https://doi. org $/ 10.1177 / 095632029700800612$

Song BH, Lee GC, Lee CH (2000): Measurement of antiviral activities using recombinant human cytomegalovirus. J. Microbiol. 38, 255-259.

Stewart JP (1999): Of mice and men: murine gammaherpesvirus 68 as a model. EBV Rep. 6, 31-35.

Sunil-Chandra NP, Efstathiou S, Nash AA (1994): The effect of acyclovir on the acute and latent murine gammaherpesvirus-68 infection of mice. Antivir Chem Chemother. 5, 290-296. https://doi.org/10.1177/095632029400500502

Svobodová J, Blaškovič D, Mistríková J (1982): Growth characteristics of herpeviruses isolated from free living small rodents. Acta Virol. 26, 256-263.

Zhang H, Bai H, Jiang T, Ma Z, Cheng Y, Zhou Y, Du L, Li M (2016): Quenching the firefly bioluminescence by various ions. Photochem. Photobiol. Sci. 15, 244-249. https://doi. org/10.1039/C5PP00432B

Zou G, Xu HY, Qing M, Wang QY, Shi PY (2011): Development and characterization of a stable luciferase dengue virus for high-throughput screening. Antiviral Res. 91, 11-19. https://doi.org/10.1016/j.antiviral.2011.05.001 